\title{
Distribution network planning considering the integration of demand-side resources
}

\author{
Xiaowei $\mathrm{Li}^{1}$, Yigang $\mathrm{Tao}^{1}$, Min $\mathrm{Li}^{1}$, Chu Chen ${ }^{1}$, Rongyao $\mathrm{Li}^{1}$, Shuqi $\mathrm{Liu}^{2}$ and ${\mathrm{Jie} \mathrm{Gu}^{2 *}}^{2}$ \\ ${ }^{1}$ Guangxi Power Grid Co., Ltd, Nanning, Guangxi, 530023, China \\ ${ }^{2}$ School of electronic information and electrical engineering, Shanghai Jiao Tong University, Shanghai, 200240, China
}

\begin{abstract}
Maximizing the potential value of demand-side resources in terms of network reliability and economy is a considerable challenge because of their time-varying and potentially complex operational characteristics. It is urgent to take the interactive relationship between supply and demand side into consideration to improve the efficiency and practicability of the distribution network planning and enhance the utilization of existing equipment. In this paper, the uncertainty of DG output and the load is first modelled, and the seasonal label information is added to the model to generate the planning-oriented scenarios of DG output and the load. Considering the integration of demand-side resources, a bi-level optimal planning model is established to minimize the annual total cost of the distribution network. The proposed model is tested on the IEEE 33-node distribution system to illustrate its feasibility and validity in distribution network planning with consideration of the integration of demand-side resources.
\end{abstract}

\section{Introduction}

The chief contribution of demand-side resources in distribution network planning is the expectation of a significant improvement in the efficiency of network operation through the associated increase in the volume of reserve capacity available to compete with supply-side capacity ${ }^{1}$. However, the increasing penetration of demandside resources, such as demand response (DR), electric vehicle (EV) and distributed generation (DG), has brought substantial uncertainties to the distribution network. It has been recognized that sole changes on the supply side, such as substation expansions and network reconstructions, are insufficient in the long run and fail to reap full environmental and economic benefits ${ }^{2}$. Therefore, it is necessary to address the issues raised by the integration of demand-side resources to achieve their full accommodation and efficient utilization.

Currently, research on distribution network planning mainly focuses on individual units of demand-side resources. In reference 3, an integrated methodology that considers DG and DR as options for planning distribution networks is researched. However, this model downplays the coordinate interaction between demand-side resources allocation and distribution network planning. As a result, the model merely contributes to reflect the impact of demand-side resources on load profiles. The same is true for reference 4 , in which only a general form of demandside resources has been considered. Reference 5 analyses the role of DG penetration, storage and incentive-based DR on distribution network planning, but the impact of EV goes unacknowledged. Therefore, in practical distribution network planning, it is of great importance to comprehensively consider the influence of all or major components of demand-side resources in order to build a collaborative planning model ${ }^{6}$.

The remainder of this paper is organized as follows. In Section 2, typical daily curves of photovoltaic output and load under multi-scenarios are proposed to deal with the problem of DG output uncertainty and seasonal variation of load. In Section 3, a bi-level coordinated distribution network planning model considering the integration of demand-side resources is built. Section 4 presents a case study to evaluate the proposed model. Conclusion is drawn in Section 5 in the interest of distribution network planning.

\section{Multi-scenarios generation}

In view of the fluctuation characteristics of DG output and the seasonal variation of load, the typical daily curves of photovoltaic (PV) output and load under multi-scenarios are generated to better capture their dynamic patterns in both temporal and spatial dimensions as well as accurately learning the probability distributions. Furthermore, the curves serve as a useful scenario set for the bi-level planning model built in the next section.

In this paper, the generative adversarial network (GAN) model, which is based on two interconnected deep neural networks, is adopted for scenario generation. New scenarios are directly generated based on historical data, without explicitly specifying a model or fitting probability distributions. In this way, the downside of existing methods based on probabilistic models is avoided.

As shown in figure 1, $12 \mathrm{PV}$ output scenarios of four

${ }^{*}$ Corresponding author's e-mail: gujie $@$ sjtu.edu.cn 
seasons under three weather conditions, namely sunny, rainy and cloudy are generated. The probability

estimations of each scenario are shown in figure 2.

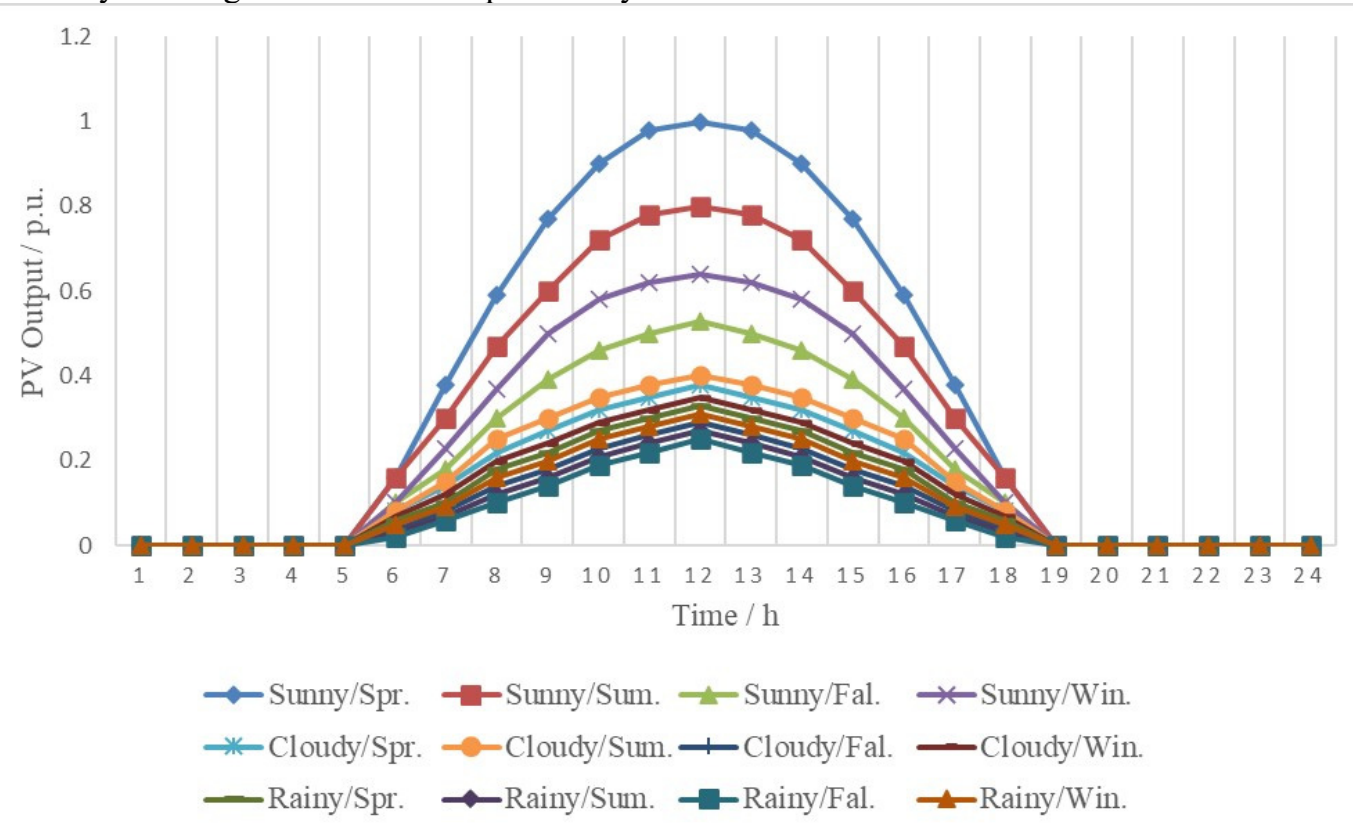

Figure 1. Daily photovoltaic output curves under 12 scenarios.

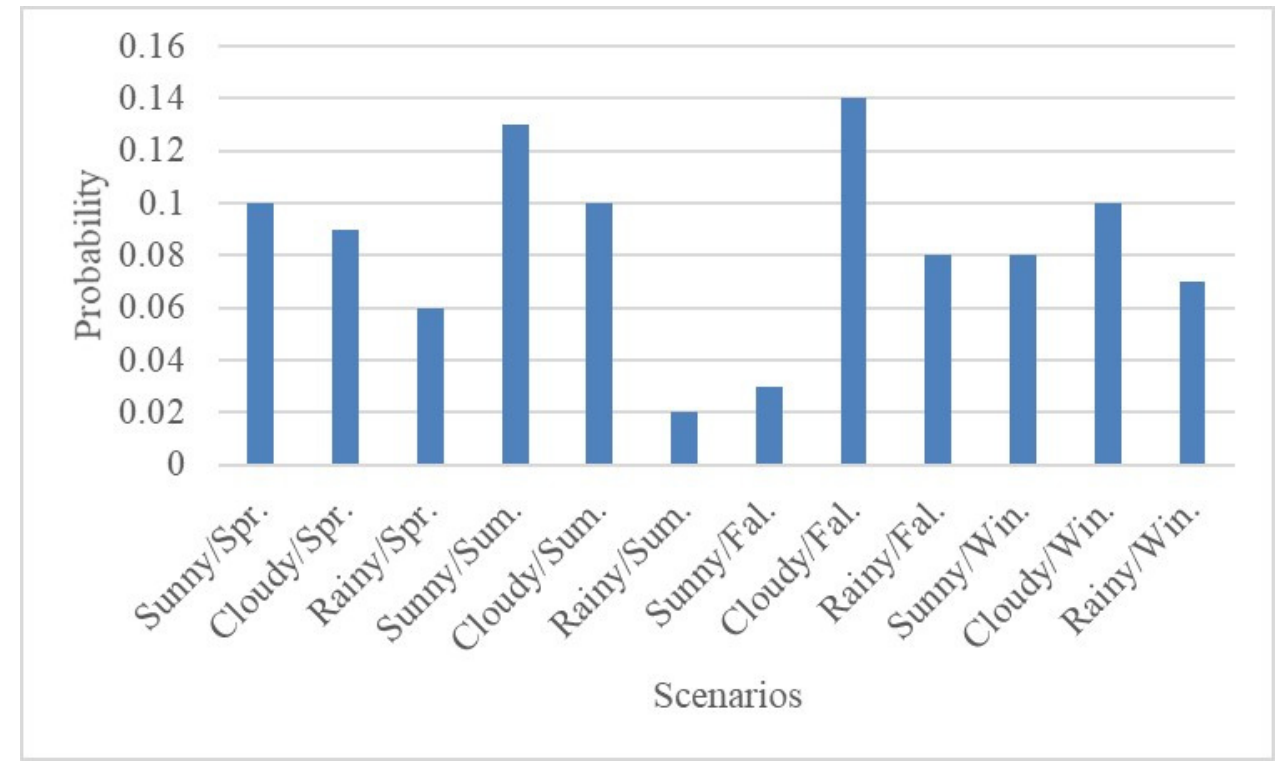

Figure 2. Probability estimations of the 12 scenarios.

Figure 3 gives the typical daily load curves in four

seasons. 

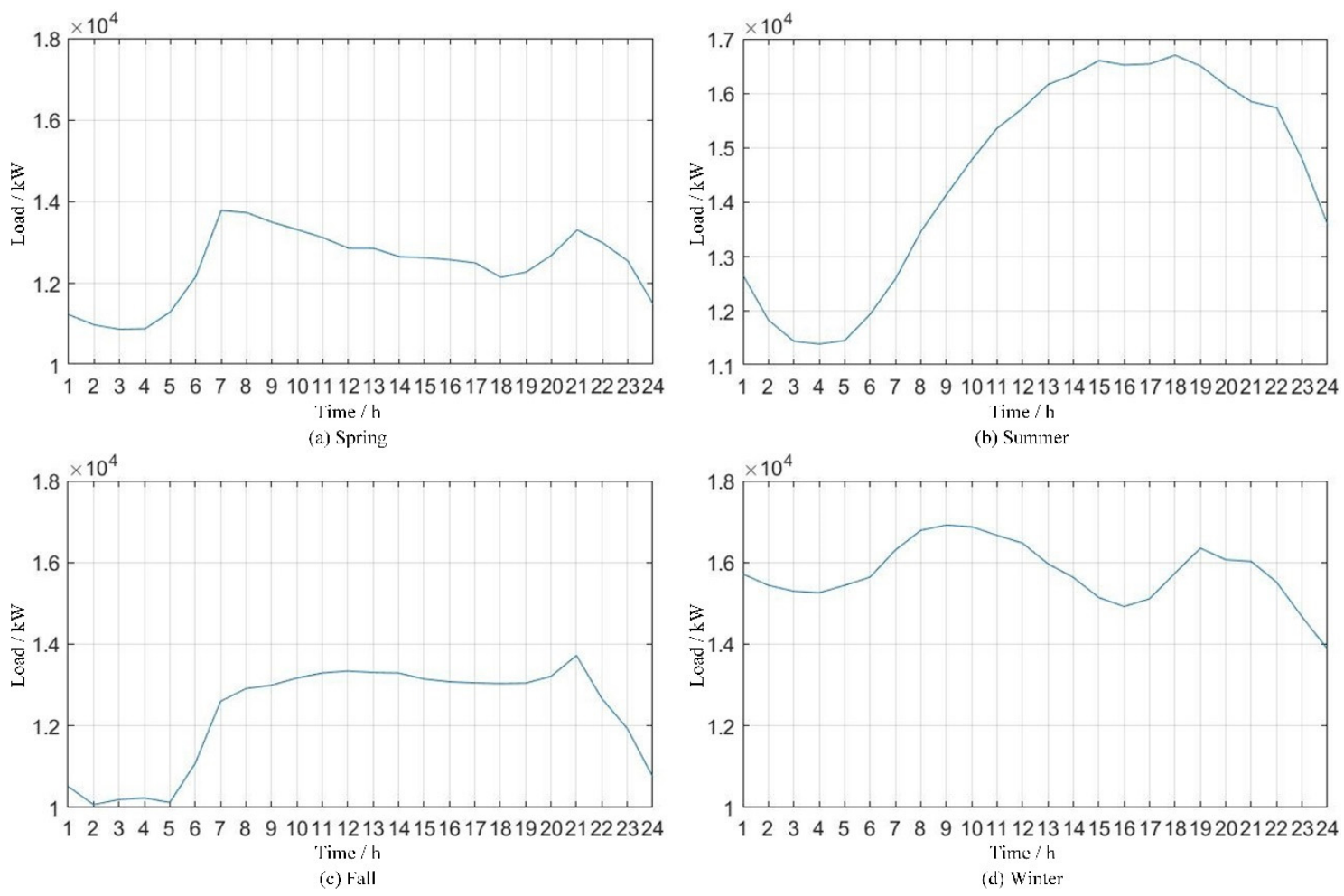

Figure 3. Probability estimation of the 12 scenarios.

\section{$3 \mathrm{Bi}$-level planning model considering demand-side resources}

The distribution network planning with demand-side resources is a nested optimization problem characterised by the coupling of planning and operation. The common characteristics of network planning problem are stated as follows:

(1) Each level independently optimises its own objective function. Decisions made at the planning level are the allocation schemes of demand-side resources with the objective of cost optimization, and 'decisions' made at the operational level are the operational parameters with the objective of reliability optimization.

(2) Objective function of each level is partially determined by variables at the other level. The operational level determines network reliability after allocation schemes are devised at the planning level.

To sum up, the two levels are interactive and exist within a predominantly hierarchical structure. Therefore, in order to investigate the full potential of demand-side resources, a bi-level distribution network planning model considering the integration of demand-side resources is presented.

\subsection{Objective function}

3.1.1 Upper planning model. The objective function of the upper planning model, as is shown in equation (1), is to minimize the total cost over the planning horizon, including the investment and operational cost of the distribution network, and the environmental benefits after the integration of demand-side resources.

$$
\min C_{e c}=\frac{r \cdot(1+r)^{y}}{(1+r)^{y}-1} \cdot C_{\text {invest }}+C_{o p}-C_{E}
$$

where $C_{e c}$ is the annual total cost of the distribution network. $r$ is the average social discount rate, which is generally taken as $8 \%$ in China. $y$ is the planning horizon. $C_{\text {invest }}$ and $C_{o p}$ are the investment and operational cost of the distribution network. $C_{E}$ is the environmental benefits brought by EV and DG.

(1) Cost of investment:

$$
C_{\text {invest }}=C_{S S f}+C_{S S e}+C_{\text {Linef }}+C_{\text {Linee }}+C_{e v}+C_{d g}+C_{I L}
$$

where $C_{S S f}$ and $C_{S S e}$ are the fixed and variable investment cost of substations. $C_{\text {Linef }}$ and $C_{\text {Linee }}$ are the fixed and variable investment cost of lines. $C_{E V}$, $C_{D G}$ and $C_{I L}$ are the investment cost of EV charging stations, DG construction and interruptible load (IL) reconstruction.

(2) Operational cost:

$$
C_{o p}=365 \sum_{i=1}^{n} \theta_{i} \cdot f_{i}
$$

where $n$ is the number of scenarios. $f_{i}$ is the daily operational cost of scenario $i$, the formula of which is shown in equation (4). $\theta_{i}$ is the occurrence probability of scenario $i$.

$$
f_{i}=\sum_{t=1}^{24}\left(\sum_{p=1}^{m} C_{b u v} \cdot E_{p, t}+\sum_{v=1}^{x} C_{e v} \cdot M_{v, t}^{e v}+\sum_{d=1}^{y} C_{d g} \cdot M_{d, t}^{d g}-\sum_{j=1}^{n} C_{s e l l} \cdot e_{j, t}\right)(4)
$$

where $C_{b u y}$ is the electricity price of the upper grid. 
$E_{p, t}$ is the power supplied by substation $p$ at time $t . C_{e v}$ and $C_{d g}$ are the operation and maintenance cost of EV charging stations and DG. $M_{v, t}^{e v}$ is the charging or discharging capacity of charging station $v$ at time $t . M_{d, t}^{d g}$ is the DG output at time $t . C_{\text {sell }}$ is the electricity price. $e_{j, t}$ is the load of node $j$ at time $t$.

(3) Environmental benefits

$$
C_{E}=P_{C_{2}} \cdot\left(\frac{M_{T}^{e v} \cdot\left(O_{f u}-O_{e v}\right)}{\rho}+\mathrm{M}_{T}^{d g} \cdot D_{C_{2}}\right)
$$

where $P_{\mathrm{CO}_{2}}$ is the operation and maintenance cost of pollution control equipment for treatment of $\mathrm{CO}_{2} . M_{T}^{e v}$ is the electricity consumption of $\mathrm{EV}$ during the planning period T. $\rho$ is the power consumption of EV per $100 \mathrm{~km}$. $O_{e v}$ and $O_{f u}$ are the carbon emission of EV and its fossil-fuelled counterpart per $100 \mathrm{~km} . \mathrm{M}_{T}^{d g}$ is the DG output within the planning period $T . D_{\mathrm{CO}_{2}}$ is the carbon emission of conventional generators.

3.1.2 Lower planning model. The lower planning model is built with the objective function of minimum voltage outage punishment.

$$
\min C_{p u n i s h}=p u_{v} \cdot \sum\left(\left(V_{k}-V_{N}\right) \cdot \delta_{v, k}\right)+p u_{R F} \cdot \sum\left(\left(S_{m}-S_{\max , m}\right) \cdot \delta_{F R, m}\right)
$$

where $p u_{v}$ and $p u_{R F}$ is the voltage and feeder capacity outage penalty coefficient. $V_{k}$ is the voltage amplitude of node $k . V_{N}$ is the nominal voltage. $\delta_{v, k}$ and $\delta_{F R, m}$ indicate the existence of voltage or feeder capacity outage at node $k$, where 1 signals positive while 0 suggests otherwise. $S_{m}$ is the carrying capacity of feeder $m$. $S_{\max , m}$ is the maximum capacity of feeder $m$.

\subsection{Constraints}

The constraints contain not only traditional electrical restrictions (for instance, limitation of DG penetration, power flow constraint, etc.), but also restrictions including demand side management and network reconfiguration.

(1) Power flow constraint

$$
\left\{\begin{array}{l}
P_{k+1}=P_{k}-\frac{r_{k+1} \cdot\left(P_{k}^{2}+Q_{k}^{2}\right)}{V_{k}^{2}}-P_{L, k+1}+P_{D G, k+1} \\
Q_{k+1}=Q_{k}-\frac{x_{k+1} \cdot\left(P_{k}^{2}+Q_{k}^{2}\right)}{V_{k}^{2}}-Q_{L, k+1}+Q_{D G, k+1} \\
V_{k+1}^{2}=V_{k}^{2}-2\left(r_{k+1} \cdot P_{k}+x_{k+1} \cdot Q_{k}\right)+\frac{\left(r_{k+1}^{2} \cdot x_{k+1}^{2}\right)\left(P_{k}^{2}+Q_{k}^{2}\right)}{V_{k}^{2}}
\end{array}\right.
$$

where $P_{k}$ and $Q_{k}$ are the active and reactive power at node $k . P_{D G, k}$ and $Q_{D G, k}$ are the active and reactive power of DG connected to node $k . P_{L, k}$ and $Q_{L, k}$ are the active power and reactive power of load at node $k$, including residential, industrial and commercial load and EV charging load. $V_{k}$ is the voltage amplitude of node $k$. $r_{k}$ and $x_{k}$ are the resistance and reactance of branch $k$.

(2) Substation capacity constraint

$$
0 \leq S_{S S, i}<S_{S S, i, \max }
$$

where $S_{S S, i, \max }$ is the maximum capacity of substation $i$. Usually, a safety margin of $10 \%$ is required. If the total peak load exceeds $90 \% S_{S S, i, \max }$, a substation expansion is needed.

(3) IL constraint

$$
0 \leq P_{I L, i}<\alpha_{\max } \cdot P_{i}
$$

where $P_{I L, i}$ is the IL at node $i$ and $\alpha_{\max }$ is the maximum IL access ratio. $P_{i}$ is the load at node $i$.

(4) DG number constraint

$$
0 \leq N_{D G}<N_{D G, \max }
$$

where $N_{D G}$ is the number of DG connected and $N_{D G \text {, max }}$ is the maximum number of DG allowed.

\subsection{Algorithms for the solution of the bi-level planning model}

The proposed integrated planning model is a nonlinear optimization problem of discrete variables, which can be effectively solved by the particle swarm optimization algorithm (PSO) ${ }^{7}$. The obtained demand-side resources allocation scheme from the upper level serves as a good initial point for reliability analysis in the lower level. Likewise, the lower level returns the daily operational cost of the distribution network to the upper for total cost calculation. Flowchart of the proposed bi-level planning model considering demand-side resources is shown in figure 4 . 


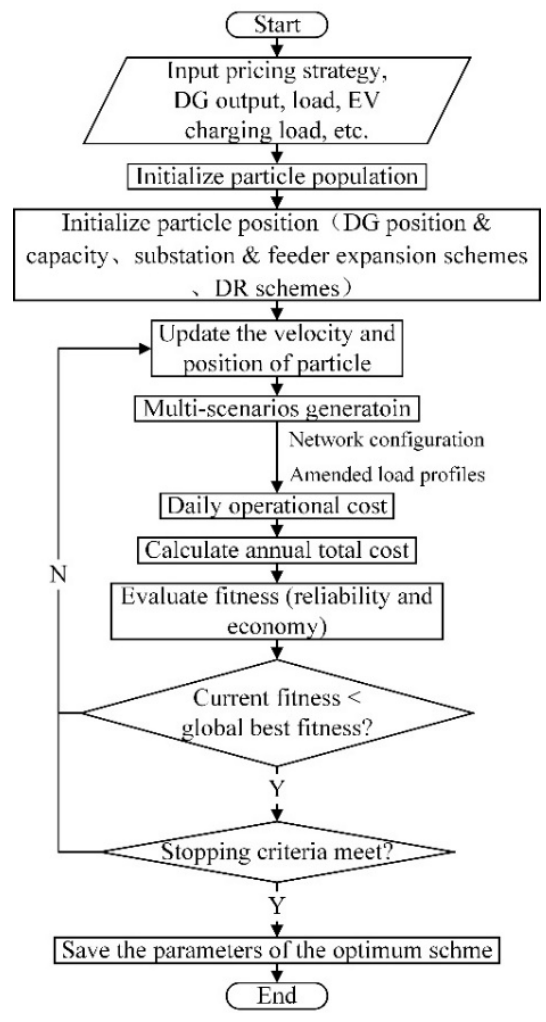

\section{Case study}

The effectiveness and advantages of the model and algorithm mentioned above, and the necessity of considering the demand-side resources are verified by simulation cases based on the IEEE 33-node distribution system.

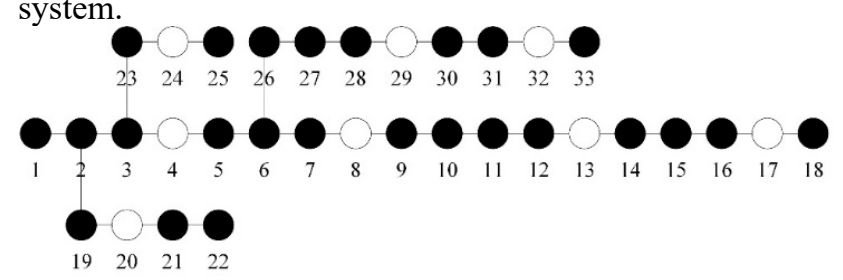

Figure 5. Structure of the IEEE 33-node distribution system.

\subsection{Parameters}

As stated by The code of planning and design of urban electric network ${ }^{8}$, the parameters of $35 \mathrm{kV} / 10 \mathrm{kV}$ substations are shown in table 1 , in which the capacity of the substations before expansion is 31.5MVA. Feeder and DG parameters are shown in table 2 and 3. Table 4 presents the electricity pricing strategy according to the data provided by a power company.

Figure 4. Flowchart of the proposed bi-level planning model.

Table 1. Parameters of $35 \mathrm{kV} / 10 \mathrm{kV}$ substations.

\begin{tabular}{cccc}
\hline Type & Capacity (MVA) & Expansion cost (yuan) & $\begin{array}{c}\text { Electricity price } \\
\text { (yuan/kWh) }\end{array}$ \\
\hline $\mathbf{1}$ & 31.5 & 0 & 0.45 \\
$\mathbf{2}$ & 63 & $10,961,600$ & 0.45 \\
$\mathbf{3}$ & 94.5 & $17,817,500$ & 0.54 \\
\hline
\end{tabular}

Table 2. Feeder parameters.

\begin{tabular}{ccccc}
\hline Type & $\begin{array}{c}\text { Maximum } \\
\text { transmission capacity } \\
\text { (MVA) }\end{array}$ & $\begin{array}{c}\text { Investment } \\
\text { (yuan) }\end{array}$ & $\begin{array}{c}\text { Resistance } \\
(\Omega / k m)\end{array}$ & $\begin{array}{c}\text { Reactance } \\
(\Omega / k m)\end{array}$ \\
\hline $\mathbf{1}$ & 10 & 50,000 & 0.7144 & 0.3208 \\
$\mathbf{2}$ & 15 & 60,000 & 0.4545 & 0.2731 \\
$\mathbf{3}$ & 20 & 80,000 & 0.2302 & 0.2482 \\
$\mathbf{4}$ & 30 & 120,000 & 0.1439 & 0.2334 \\
$\mathbf{5}$ & 35 & 140,000 & 0.1151 & 0.2262 \\
$\mathbf{6}$ & 40 & 160,000 & 0.0916 & 0.2181 \\
$\mathbf{7}$ & 57 & 228,000 & 0.0458 & 0.1958 \\
$\mathbf{8}$ & 78 & 312,000 & 0.0407 & 0.192 \\
$\mathbf{9}$ & 118 & 472,000 & 0.0253 & 0.1834 \\
\hline
\end{tabular}

Table 3. DG parameters.

Capacity (MW) Investment (yuan)

\begin{tabular}{rc}
\hline $\mathbf{1 0}$ & 400,000 \\
$\mathbf{2 0}$ & 780,000 \\
$\mathbf{3 0}$ & $1,150,000$ \\
\hline
\end{tabular}


Table 4. Electricity pricing strategy.

\begin{tabular}{lc}
\hline \multicolumn{1}{c}{ Periods } & Electricity price $(\mathrm{yuan} / \mathrm{kWh})$ \\
\hline Peak (10: 00-15: 00; 18: 00-21: 00) & 400,000 \\
Flat (7: 00-10: 00, 15: 00-18: 00; 21: 00-23: 00) & 780,000 \\
Valley (23: 00-7: 00) & $1,150,000$ \\
\hline
\end{tabular}

In order to achieve precise simulation of the distribution network, the following assumptions are made:

(1) The access locations of DG are 5,8,14,17,21,25 and 32 with the maximum number of DG being 2 .

(2) To facilitate the study on the spatial characteristics of EV charging load, the IEEE 33-node distribution system is divided into three parts, namely the residential,

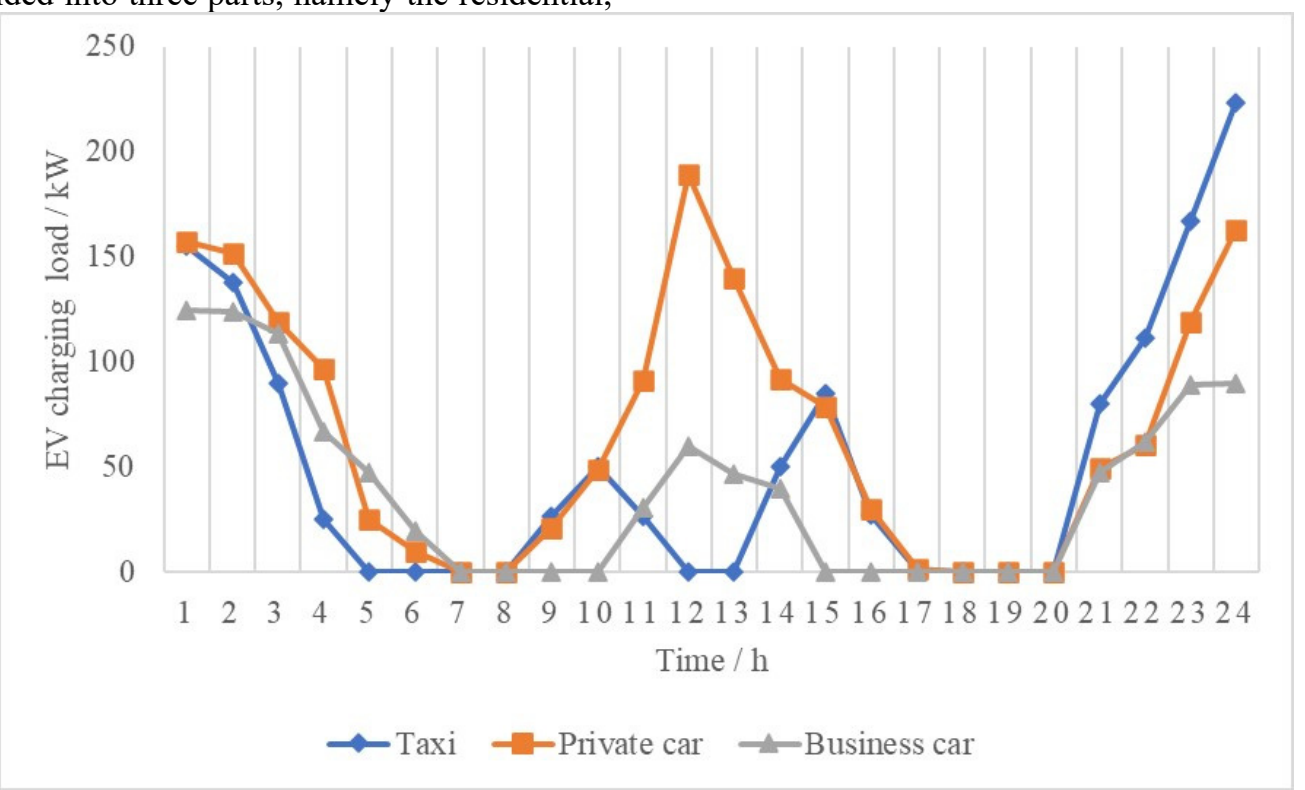

Figure 6. Daily charging load profiles of three types of EV.

\subsection{Results}

Five different planning schemes are devised for comparison:

(1) Scheme 1 is the optimum scheme which adopts the proposed bi-level planning model considering the industrial and commercial districts. The EV charging stations are installed at node 12,19 and 29. Figure 6 shows the daily charging load profiles of three types of EV.

(3) The planning horizon is 10 years.

(4) The conventional load grows at an annual rate of $5 \%$.

Table 5. Results of the optimization planning results for demand-side resources.

\begin{tabular}{|c|c|c|c|c|c|}
\hline Planning schemes & 1 & 2 & 3 & 4 & 5 \\
\hline $\begin{array}{c}\text { Maximum substation } \\
\text { capacity after expansion } \\
\text { (MW) } \\
\end{array}$ & 63 & 94.5 & 63 & 94.5 & 63 \\
\hline $\begin{array}{l}\text { Reconstructed feeders } \\
\text { with corresponding } \\
\text { capacity (MVA) }\end{array}$ & $\begin{array}{c}1(78) 2(57) \\
3(40) 4(40) \\
5(30) 12(30) \\
27(20)\end{array}$ & $\begin{array}{c}1(78) 2(57) \\
3(40) 4(40) \\
5(30) 7(20) \\
12(30) \\
27(20) \\
\end{array}$ & $\begin{array}{c}1(78) 2(57) 3(40) \\
4(40) 5(30) 7(20) \\
12(30) \\
27(20)\end{array}$ & $\begin{array}{c}1(78) 2(57) \\
3(40) 4(40) \\
5(30) 7(20) \\
12(30) 23(15) \\
27(20) \\
\end{array}$ & $\begin{array}{c}1(78) 2(57) \\
3(40) 4(40) \\
5(30) 7(20) \\
12(30) 23(1500) \\
27(2000) \\
\end{array}$ \\
\hline $\begin{array}{c}\text { DG access locations with } \\
\text { corresponding capacity } \\
\text { (MW) }\end{array}$ & $\begin{array}{l}12(30) \\
32(30)\end{array}$ & $\begin{array}{l}17(30) \\
32(30)\end{array}$ & $\begin{array}{l}17(30) \\
32(30)\end{array}$ & - & - \\
\hline $\begin{array}{l}\text { IL implementation } \\
\text { locations with } \\
\text { corresponding ratio }\end{array}$ & $\begin{array}{l}19(30 \%) \\
24(30 \%)\end{array}$ & - & $\begin{array}{l}23(30 \%) \\
24(30 \%)\end{array}$ & $\begin{array}{l}23(30 \%) \\
24(30 \%)\end{array}$ & - \\
\hline
\end{tabular}


The comparison of cost and reliability among schemes is shown in table 6 .

Table 6. Cost and reliability of the optimization planning results for demand-side resources.

\begin{tabular}{c|c|c|c|c|c}
\hline Cost and reliability indexes & 1 & 2 & 3 & 4 & 5 \\
\hline $\begin{array}{c}\text { Annual expansion cost of substations } \\
\text { (yuan) }\end{array}$ & $6.0288 \times 10^{6}$ & $9.7996 \times 10^{6}$ & $6.0288 \times 10^{6}$ & $2.0803 \times 10^{6}$ & $6.0288 \times 10^{6}$ \\
\hline $\begin{array}{c}\text { Annual reconstruction cost of feeders } \\
\text { (yuan) }\end{array}$ & $1.1800 \times 10^{6}$ & $1.4850 \times 10^{6}$ & $1.4850 \times 10^{6}$ & $2.2732 \times 10^{6}$ & $2.8272 \times 10^{6}$ \\
\hline $\begin{array}{c}\text { Annual construction cost of EV } \\
\text { charging stations (yuan) }\end{array}$ & $2.4389 \times 10^{5}$ & $2.4389 \times 10^{5}$ & 0 & $2.4389 \times 10^{5}$ & 0 \\
\hline Annual construction cost of DG (yuan) & $1.9580 \times 10^{5}$ & $4.8096 \times 10^{5}$ & $4.8096 \times 10^{5}$ & 0 & 0 \\
\hline Annual construction cost of IL (yuan) & $1.2440 \times 10^{5}$ & 0 & $1.2440 \times 10^{5}$ & $1.2440 \times 10^{5}$ & 0 \\
\hline $\begin{array}{c}\text { Annual operation and maintenance } \\
\text { cost of EV charging stations (yuan) }\end{array}$ & $1.1388 \times 10^{5}$ & $1.1388 \times 10^{5}$ & 0 & $1.1388 \times 10^{5}$ & 0 \\
\hline $\begin{array}{c}\text { Annual operation and maintenance } \\
\text { cost of DG (yuan) }\end{array}$ & $2.8328 \times 10^{5}$ & $2.8328 \times 10^{5}$ & $2.8328 \times 10^{5}$ & 0 & 0 \\
\hline Annual compensation of IL (yuan) & $8.8997 \times 10^{5}$ & 0 & $8.8997 \times 10^{5}$ & $8.8997 \times 10^{5}$ & 0 \\
\hline $\begin{array}{c}\text { Annual electricity purchasing cost } \\
\text { (yuan) }\end{array}$ & $3.5633 \times 10^{7}$ & $3.5836 \times 10^{7}$ & $3.2608 \times 10^{7}$ & $3.6537 \times 10^{7}$ & $3.5625 \times 10^{7}$ \\
\hline Annual total sales of electricity (yuan) & $3.2217 \times 10^{7}$ & $3.2314 \times 10^{7}$ & $3.0001 \times 10^{7}$ & $3.2790 \times 10^{7}$ & $3.1204 \times 10^{7}$ \\
\hline Environmental benefits (yuan) & $2.1171 \times 10^{6}$ & $2.1171 \times 10^{6}$ & $1.0701 \times 10^{6}$ & $1.0001 \times 10^{6}$ & 0 \\
\hline $\begin{array}{c}\text { Annual total cost of the distribution } \\
\text { network (yuan) }\end{array}$ & $1.1452 \times 10^{7}$ & $1.2411 \times 10^{7}$ & $1.2372 \times 10^{7}$ & $1.3225 \times 10^{7}$ & $1.3752 \times 10^{7}$ \\
\hline Voltage outage punishment (p.u.) & 6443.5839 & 6932.4087 & 6672.7264 & 7292.0265 & 6488.9620 \\
\hline Feeder outage punishment (p.u.) & 1136.8850 & 1291.6769 & 1214.3936 & 1252.6859 & 1139.7579 \\
\hline
\end{tabular}

\subsection{Analysis}

(1) Compared with Scheme 2, the annual total cost of the distribution network under Scheme 1 drops by $7.73 \%$, which indicates that DR can bring more economic benefits to the distribution network with lower implementation cost, and alleviate the problem of power shortage during peak hours. Furthermore, the implementation of IL in nodes with heavier load achieves higher economic benefits.

(2) Compared with Scheme 3, the annual environmental benefits under Scheme 1 increases by $49.45 \%$, which suggests that EV enjoys a greater level of environmental friendliness. In the meantime, from the perspective of income, Scheme 1 proves to be more profitable. However, the peak load escalates after the access of EV, which calls for higher substation and feeder capacity.

(3) Granted that there is a certain amount of construction, operation and maintenance cost involved in the access of DG, but the annual total cost of the distribution network under Scheme 1 drops by $13.33 \%$ compared with Scheme 4. This is because the access of DG effectively lightens the need for a network upgrade. In this way, the cost of substation and feeder expansion is saved while the environmental benefits increase.

\section{Conclusion}

This paper addresses the issue of distribution network planning considering demand-side resources. First, multiple scenarios are generated to depict the uncertainty of DG output and the load. Based on this, a bi-level planning model is built with consideration of the potential benefits of demand-side resources at operation and economic levels as well as reliability enhancement. At last, the feasibility of the proposed model is confirmed through a case study and the following conclusions are drawn:

(1) The comparison between the proposed planning scheme with its counterparts shows that demand-side resources can provide additional energy and capacity resources without installing new generation infrastructure, namely a network upgrade. Also, the integration of demand-side resources can enhance distribution network reliability and security.

(2) Demand-side resources produce higher economic and environmental benefits at a lower cost. Implementation of distribution network planning with no account of demand-side resources integration is likely to produce a network reconstruction scheme that may disagree with the real situation.

\section{Acknowledgments}

This work is supported by Project Supported by National Key Research Program of China (2016YFB0900100): "High-ratio Renewable Energy Grid-connected Power System Planning and Operation Basic Theory" and Scientific Project of China Southern Power Grid Company Limited (046700KK52190001): "Research on Key Technologies of Distribution Network Planning Adapted to Distributed Generation Integration".

\section{References}

1. Karangelos, E., Bouffard, F. (2012) Towards Full Integration of Demand-Side Resources in Joint Forward Energy/Reserve Electricity Markets. J. IEEE Transactions on Power Systems, 27: 280-289. 
2. Eric, H., Richard C. Demand Side Resources and Reliability, New England Demand Response Initiative, Mar. 20, 2002 (32 pages).

3. Zeng, B., Zhang, J., Yang, X., Wang, J., Dong, J., \& Zhang, Y. (2014) Integrated Planning for Transition to Low-Carbon Distribution System with Renewable Energy Generation and Demand Response. J. IEEE Transactions on Power Systems, 29: 1153-1165.

4. Khodaei, A., Shahidehpour, M., Bahramirad, S. (2011) SCUC with hourly demand response considering intertemporal load characteristics. J. IEEE Transactions on Smart Grid, 2: 564-571.

5. Wang. S. 2018. Distribution Network Energy Storage Configuration Method Research Considering General Demand Side Resources. Unpublished master's thesis, North China Electric Power University. (in Chinese)

6. Zhang, J.X. 2017. Optimization Method of Urban Distribution Network Planning Based on the Energy Internet. Unpublished master's thesis, North China Electric Power University. (in Chinese)

7. Kennedy J., Eberhart R. (1995) Particle Swarm Optimization. In: Proceedings of IEEE International Conference on Neural Networks. Perth. pp. 19421948

8. State Grid. (2006) The code of planning and design of urban electric network. China Electric Power Press, Beijing. (in Chinese) 